\title{
Georges Bataille. Comunidad y comunicación
}

\section{Georges Bataille. Community and Communication}

\author{
María GARCÍA PÉREZ \\ Universidad de Murcia \\ themylam@gmail.com
}

Recibido: 08/02/2013

Aceptado: 20/02/2014

\section{Resumen}

Por la heterodoxia de su obra, Georges Bataille se nos presenta como un enigma a descifrar. Encontrar ciertos resortes que nos guíen en lo prolífico y heterogéneo de su producción se hace ineludible si tenemos en cuenta la profundidad e importancia de las nociones filosóficas y políticas que destaca y a las que transgrede. En este caso nos adentramos en los conceptos de comunidad y comunicación al hilo del pensamiento impolítico que R. Esposito le atribuye pero siguiendo fundamentalmente el descubrimiento de Derrida en La escritura y la diferencia a propósito de Hegel, la muerte y el sacrificio.

Palabras clave: Bataille, comunidad, comunicación, erotismo, derroche.

\begin{abstract}
Because of the heterodoxy of his work, Georges Bataille appears to us as a deciphering crux. If we bear in mind the depth and importance of the philosophical and political notions that stands out and that he transgrede, to find certain springs that guide us into his prolific and heterogeneous production becomes unavoidable. Doing so, community and communication concepts raise up dealing with the discourteous thought that R. Esposito attributes to him but following fundamentally Derrida's discovery in The writing and the difference about Hegel, the death and the sacrifice.

Keywords: Bataille, community, communication, eroticism, spending.
\end{abstract}




\section{Introducción}

El 10 de julio de 2012 se cumplieron cincuenta años de la muerte de Georges Bataille (Billom, 10 de septiembre de 1897-París, 8 de Julio de 1962), sin lugar a dudas una de las figuras más destacadas de la filosofía del siglo XX. Si bien ignorado por la mayor parte de la academia y sólo estudiado en el inicio en su faceta de esteta teórico del erotismo, donde sus contribuciones son innegables, hoy se recupera en clave política. En aquél primer ámbito que caló desde luego por su fuerza transgresora, esto es, en la dimensión de la reflexión sobre el erotismo a través de la novela y el ensayo, destacan obras como Historia de un ojo, El azul del cielo, Madamme Edwarda, el Muerto o, por otra parte, El erotismo o Las lágrimas de Eros. Pero en Bataille hay mucho más, prueba de ello es su reinterpretación a través de figuras como Roberto Esposito o Jean-Luc Nancy: La noción de gasto junto con La parte maldita, El problema del Estado o La estructura psicológica del fascismo y otros tantos textos nos devuelven a un Bataille completo, no sólo atento a los fenómenos del arte o la sexualidad, sino también y con especial profundidad, al ámbito político e histórico-social. Con todo, se podría decir que aun hay un tercer Bataille, un Bataille místico que habla de una "experiencia interior" en el "extremo de lo posible" y cuya escritura hace temblar al academicismo y el cientificismo que requieren los artículos y los ensayos pero, también, al estilo literario de cualquier historia novelada o cualquier poema. La dura crítica de Jean Paul Sartre que le acusaba de nuevo místico puso su mirada sobre este aspecto de la obra de Bataille tras la publicación de La experiencia interior a la que le seguirían El Culpable y Sobre Nietzsche, voluntad de suerte.

Fernando Savater en su prólogo a El aleluya y otros textos, bajo el título "Bataille, demasiado para el cuerpo", aludía a una pluralidad de identidades en Bataille. Desde luego el pensador francés se presta a este juego de máscaras con la utilización de seudónimos como Lord Auch o Pierre Angélique pero, sobre todo, como vemos, por la heterogeneidad de su obra: "un poliedro de infinitas caras" esta apariencia de dispersión inconmensurable de registros de escritura subyace una línea continua, un esfuerzo, ciertamente nada sistemático, por mostrar todas las caras de un mismo fenómeno: el de la comunicación como condición de posibilidad de toda soberanía y de un especial tipo de comunidad. Descubrir esta línea, como ya nos advirtiera Miguel Morey, no es fácil: "Bataille aún no ha hallado el auditorio que recoja sus escritos en una unidad de comprensión y los convierta en una obra. Bataille aun no tiene la obra que puede (y que sin duda, llegará) a tener: somos demasiado torpes aún para reconocer el hilo melódico que la articula de principio a fin, tarareamos,

\footnotetext{
${ }^{1}$ A. Campillo, "La comunidad infinita", en Georges Bataille, El Estado y el problema del fascismo, Valencia, Pre-textos/Univ. De Murcia, 1993, p. 2.
} 
a lo sumo, vagamente, algún estribillo que se le parece"². Tal vez de ahí la discontinuidad temporal en los estudios sobre este autor que, quizá, no se presta a ser agotado fácilmente $\mathrm{y}$, por tanto, tampoco a ser analizado sin dejar al menos cierta sensación de zozobra por aquello que inevitablemente quedó fuera de una explicación coherente, racional. Tal vez aun sigamos tarareando estribillos, el presente artículo trata al menos de componer alguna otra parte de la melodía incompleta.

No obstante, hallar esa nervadura en los textos del francés no ha de convertirse en un mero ejercicio de erudición, hacer esto sería traicionar a Bataille limitándonos al campo específico de lo académico, de lo útil y lo racional, de lo que sirve a un determinado fin. Lo que de fondo anima aquí es la posibilidad de repensar el concepto de democracia desde las coordenadas de la comunidad batailleana, en las antípodas de la teología política cuyo máximo exponente es Carl Schmitt, poniendo en valor la noción de soberanía desde lo impensado en ella: "Su cuestionamiento del capitalismo (...), adoptó un gesto de vuelta a lo primitivo encajable con ciertos ideales marxistas tales como la sospecha de lo político, el antiindividualismo, la sugerencia de comunidades sin mediación, o la superación del Estado y la propiedad privada. (...) $\mathrm{Su}$ nuevo concepto de soberanía, que debe analizarse poniendo como trasfondo el de Schmitt, exhibirá claramente la influencia de un nuevo compañero de viaje, Nietzsche" ¿3. ¿Por qué esta tarea, decimos, no es útil?, es sencillo, el gesto mismo constituye un gasto improductivo en tanto en cuanto el tipo de comunidad que tratamos de vislumbrar no es capaz de tener una delimitación conceptual clara y, en consecuencia, sobre ella el pensamiento nunca puede detenerse en conclusiones definitivas. Como ya afirmó Derrida, la democracia siempre está por venir ${ }^{4}$, jamás está acabada, no puede alcanzarse en ella perfección, es aquel noúmeno kantiano que espolea al pensamiento a ir más allá de sí, a romperse y desgarrarse una y otra vez para permanecer siempre al menos de una parte en el reino del no-saber.

\section{El fracaso de Hegel}

Y fue precisamente Jacques Derrida en La escritura y la diferencia quien supo identificar el que quizá sea uno de los textos más importantes de Georges Bataille: Hegel, la muerte y el sacrificio. En ese breve ensayo encontramos un rigor filosófico que coloca al francés a la altura del alemán, en el que el primero es capaz de dialo-

\footnotetext{
${ }^{2}$ M. Morey, "Excessere omnes... invitación a la lectura de Georges Bataille" en Psiquemáquinas, Barcelona, Montesinos, 1990, p. 183.

${ }^{3}$ A. Galindo, La soberanía. De la teología política al comunitarismo impolítico, en Res Pública, 2003, p. 120.

${ }^{4}$ Sobre esta cuestión puede acudirse a J. Derrida, Canallas, dos ensayos sobre la razón, trad. Cristina de Peretti, Madrid, Trotta, 2005.
} 
gar con el segundo. Además en ese escrito se halla el núcleo de toda la reflexión de Bataille que ahora rastreamos expresado con una coherencia filosófica que será difícil de encontrar en otras obras y que tiene el valor de apuntar al máximo exponente del idealismo del siglo XIX a través de la lectura que Alexandre Kojève hiciera de él. Podemos esbozar un breve análisis de este nudo gordiano de la reflexión batailleana:

Para Bataille, igual que para Hegel, la emergencia del hombre supone la irrupción de una intimidad en el seno de la exterioridad, esto es, de una conciencia objetivante que torna a presencia a la Naturaleza operando el posicionamiento objetual de toda cosa, animal o vegetal, inscribiendo la separación en el continuum del mundo previo a ella, destruyéndolo, negándolo. Esta es la primera tesis de Bataille recogida con posterioridad también en Teoría de la Religión (1948) y con la que arranca Hegel, la muerte y el sacrificio: El surgimiento del carácter humano de la humanidad en la Naturaleza culmina en la configuración de una intimidad oscura en el seno de la exterioridad que era el mundo inmanente y que desde ese momento se hace irrecuperable. "Todo animal está en el mundo como el agua dentro del agua" 5 es como la ola en el océano. Bataille se sirve aquí de la metáfora para dar cuenta de lo otro del hombre que, sin embargo, está en el hombre: la animalidad, su vida biológica, zoè. El recurso a la metaforología es en este caso necesario: el discurso significativo no puede dar cuenta del sin-sentido y la mirada animal es, sin lugar a dudas, aquello que está más allá del sentido humano, es otra mirada, lo absolutamente Otro. Aquí, la poesía se hace solidaria de lo asignificativo.

Ocurre además que esta negación no es sólo negación al exterior, de la continuidad natural, sino que la negación es también negación de la propia continuidad animal del ser humano y, por tanto, supone el sacrificio de la propia animalidad, "lo que hace del hombre -según la expresión de Heidegger- un ser para la muerte (Sein zum Tode) o -según la expresión del mismo Kojève- 'la muerte que vive una vida humana'" ". Así, la fuerza mostrenca de la conciencia humana que es esa interioridad es capaz de realizar la separación objetivante de las cosas del mundo. Se trata de "'la idea central y última de la filosofía hegeliana', a saber: 'la idea de que el fundamento y origen de la realidad objetiva (Wirklichkeit) y de la existencia empírica (Dasein) humanas son la Nada que se manifiesta en tanto Acción negativa y creadora, libre y consciente de sí misma'"’ . Brota con ello la separación sujeto-objeto.

\footnotetext{
${ }^{5}$ G. Bataille, Teoría de la religión, texto establecido por Thadée Klossowski, trad. de F. Savater, Madrid, Taurus, 1991, p. 22.

${ }^{6}$ G. Bataille, "Hegel, la muerte y el sacrificio", en La felicidad, el erotismo y la literatura ensayos 1944-1961, selecc., trad. y prólogo de Silvio Mattóni, Buenos Aires, Adriana Hidalgo editora S.A., 2001, p. 296.

${ }^{7}$ Ibidem, p. 284.
} 
Pero Bataille, nos dice Jacques Derrida en La escritura y la diferencia, "se ha tomado en serio a Hegel" y ha mostrado su fracaso. Y así es si tenemos en cuenta que su concepto de soberanía emerge de las profundidades inexploradas de la Fenomenología del Espíritu, de lo impensado, tal vez por impensable, que allí quedó. Derrida lo explica a la perfección, la soberanía batailleana no es ya el señorío hegeliano pues aquélla muestra a la dialéctica que culmina en la síntesis auto objetivante su límite y su derrota. Para Bataille el amo hegeliano no es más que otro esclavo porque la verdadera soberanía ni siquiera se busca a sí misma y, mucho menos, al sentido: "El señorío tiene un sentido. La puesta en juego de la vida es un momento de la constitución del sentido, en la presentación de la esencia y de la verdad. Es una etapa obligada en la historia de la conciencia de sí y de la fenomenalidad, es decir, de la presentación del sentido (...) Risa a carcajadas de Bataille" 9 .

Sí, Derrida se ha tomado en serio a Bataille: ha sabido identificar la torcedura a la que somete a la fenomenología hegeliana, el temblor que inocula en la dialéctica del amo y el esclavo base para la posterior teoría marxiana sobre la emancipación a través de la clase obrera. La dialéctica estalla en mil pedazos, queda paralizada, aniquilada cuando la negatividad ya no es un momento de la construcción de sentido sino puro derroche improductivo, cuando la negatividad ya no es negatividad sino una auténtica Nada que se hermana con la muerte porque "lo que es soberano por definición, no sirve" ${ }^{10}$. Si se quiere, podemos decir que Bataille realiza aquí una antropología del gasto que le separa de raíz de toda concepción humana anclada a la utilidad, a la mejora de las capacidades en pro de una finalidad, de la auto-objetivación de la conciencia para alcanzar una sabiduría que al cabo se muestra servil. De este modo, en adelante podrá sustentar aquella economía general capaz de dar cuenta de los fenómenos de lo inservible, de aquello que no se acomoda a la cadena mediosfines y, así, a tener plena significación: la fiesta, el arte, la literatura, el erotismo, la muerte, etc. La sabiduría soberana, en cambio, será aquella que lleve hasta sus últimas consecuencias la vinculación del humano a la finitud, lo que Hegel supo ver pero de lo que, en última instancia, quiso huir. Por tanto, se trata de asumir la angustia en toda su radicalidad, hasta las lágrimas y la risa.

En una nota al pie Bataille nos habla de la posibilidad de un nuevo tipo de misticismo a este respecto, "un misticismo consciente (...) -donde- El místico ateo, consciente de sí, consciente de tener que morir y desaparecer, viviría, como Hegel dice evidentemente de sí mismo 'en el desgarramiento absoluto'; pero para Hegel se trata

\footnotetext{
${ }^{8}$ J. Derrida, "De la economía restringida a la economía general. Un hegelianismo sin reserva", en La escritura y la diferencia, trad. de P. Peñalver Gómez, Barcelona, Anthropos, 1989, p. 345.

${ }^{9}$ Ibidem, pp. 348-350.

${ }^{10}$ G. Bataille, "Hegel, la muerte y el sacrificio", en La felicidad, el erotismo y la literatura ensayos 1944-196, cit., p. 306.
} 
sólo de un periodo. A la inversa de Hegel, el místico ateo no saldría de allí aún "contemplando lo Negativo frente a frente', pero no pudiendo nunca trasponerlo en Ser, rehusando hacerlo y manteniéndose en la ambigüedad" 11 . En el fondo Sartre tenía razón cuando tras leer La experiencia interior lanzó su acusación de "nuevo místico" contra Bataille, lo que quizá no observó fue la radicalidad de esa novedad porque en ese misticismo no encontramos ni un rastro de trascendencia, lo que hallamos en el corazón de la soberanía batailleana es la plena inmanencia perdida para el humano de la vida animal, aquella continuidad que alberga "un no se qué de dulce, de secreto y doloroso"12 y que quedó rota con la aparición del útil que instaura la distinción sujetoobjeto. Por tanto, la Historia, desde el origen mismo del ser humano, es una historia de pérdida absoluta e irrecuperable, tan absoluta e irrecuperable como lo es la vida de un ser humano que muere: Historia como tragedia.

Lo importante hasta aquí es comprender el núcleo fenomenológico y antropológico de la soberanía a partir de esta Negatividad sans emploi que polemiza con la $\mathrm{Fe}$ nomenología del Espíritu hegeliana. A esto podemos añadir que quizá Hegel, la muerte y el sacrificio (1955) sea a Teoría de la Religión (1948) lo que La noción de gasto (1929) es a La parte maldita (1949) esto es, un lúcido, riguroso y conciso compendio de lo que puede ser desplegado en una reflexión más amplia o, mejor, de lo que insiste bajo todas y cada una de las reflexiones. En este caso, como se observa, no estamos ante una anticipación temporal de un mismo tema, sino de su repetición posterior en la forma del artículo. En cualquier caso, esta línea trazada en la vasta y heterodoxa obra de Bataille, de ser cierta, nos dice que no cabe hacer partes, separar temas por estilos de escritura: una única y constante preocupación estalla en Bataille en la forma de una mirada caleidoscópica que abarca desde la economía hasta la antropología, desde la estética a la religión, desde la política al erotismo, pero que se condensaría y se fundamentaría filosóficamente en esta discusión con Hegel: se trata de su teoría del excedente donde, la soberanía, desde esta perspectiva, es aquello que excede y está más allá del sentido.

Así, de este núcleo fenomenológico podemos dar el paso a lo que Bataille denominó como Economía general y que compone otro de los vértices indispensables para la comprensión (en lo posible o en su extremo) de los conceptos de comunidad y comunicación.

\footnotetext{
${ }^{11}$ Ibidem, p. 293.

${ }^{12} \mathrm{G}$. Bataille, Teoría de la religión, cit., p. 26.
} 


\section{Hacia una economía general}

La noción de gasto, artículo que vio la luz por primera vez en la revista Critique sociale en 1933 y escrito bajo la influencia de la lectura de Ensayo sobre el don de Marcel Mauss, se editó junto con La parte Maldita, libro de 1949, y esto porque uno constituye un adelanto breve del otro más desarrollado. En ambos se explicita una teoría económica que quiere superar a las dos teorías clásicas que dominaban el mundo en el siglo XX: el socialismo marxista y el liberalismo smithiano: "En cierto sentido, yo creo que todo el pensamiento de Georges Bataille (...) puede considerarse como una crítica radical y sistemática a los supuestos básicos de la Economía moderna"13. En efecto, éste es un enfoque posible porque de lo que se trata es de hacer visible, mediante la disciplina económica, que por tanto ha de ser revisada y ampliada, todos aquellos fenómenos que se habían ocultado y habían resistido a ser explicados. La crítica consiste en poner de relevancia un principio capaz de dar cuenta de todos esos movimientos humanos que, como constante, se encuentran en todas las sociedades de un modo u otro: el principio de gasto.

No obstante, este principio aplicado a la economía encuentra su raíz en el rebasamiento de la fenomenología hegeliana como antes pudimos analizar. Tiene un origen, pues, anterior si se quiere: es un principio ontológico, inviscerado en el mundo y rector de esa parte maldita que es maldita por no extraerse de ella ningún beneficio, por ser puro derroche. Por este motivo la historia ya no puede ser comprendida desde el paradigma de la noción de progreso, en este caso, de progreso material en cuanto acumulación de riquezas y progresiva independencia y dominio de la Naturaleza. Por el contrario, la historia humana "está sometida a una tensión dialéctica irresoluble, y por tanto trágica, entre dos movimientos de dirección contraria: por un lado, el principio de ganancia, que explica las actividades de producción, apropiación y acumulación; por otro lado, el principio de pérdida, que explica las actividades de destrucción, donación y derroche" ${ }^{14}$. Ahora bien, lejos de lo que se pudiera pensar y para seguir ahondando en la crítica a la Economía moderna, desde ahora Economía restringida, para Bataille de ambos principios es el de derroche o pérdida el que rige verdaderamente las actividades humanas y esto porque en el fondo es el que se encuentra a la base de los procesos que dan origen a la vida tal y como la conocemos: el ejemplo lo da el derroche energético que proviene del Sol. Principio de vida y de su desarrollo es el exceso, pero también del acabamiento y la finitud, porque la vida misma también se derrocha: el sexo (como donación de más vida) y la muerte (como dilapidación de vida) son los dos fenómenos básicos por los que en la vida biológica se concreta ese principio de gasto improductivo, de lujo.

\footnotetext{
${ }^{13}$ A. Campillo, Contra la Economía Ensayos sobre Bataille, Granada, Comares, 2001, p. 60.

${ }^{14}$ Ibidem, pp. 60-61.
} 
¿Qué tiene que ver todo esto con los conceptos de comunidad y comunicación? La respuesta más inmediata pasa por afirmar que una y otra son formas de derroche, que, por lo tanto, deben incluirse en el estudio de esta Economía General. La razón básica es que Bataille rechaza uno de los dogmas básicos que rigen la teoría económica de su tiempo: las relaciones humanas no son relaciones puramente económicas en el sentido de que no se rigen exclusivamente por el principio de ganancia, pero tampoco pueden agotarse en el mero contractualismo político. Muy al contrario, lo que posibilita la construcción comunitaria y el diálogo con otros seres humanos tiene como epicentro la cuestión sexual. Pero el sexo, al igual que ocurría con la muerte, difiere del hombre al animal: del mismo modo que la muerte del animal a diferencia de la muerte humana, no es vivida desde la autoconciencia angustiosa del acabamiento de sí como ser singular, pues el animal vive inmerso en la continuidad natural inmanente, la sexualidad ya no se concreta como un impulso ciego que lleva sin más a la reproducción. En el reino animal no existe el individuo, esto es, la separación y el aislamiento que constituyen al humano. Y estos dos rasgos reconfiguran los elementos básicos en los que transcurre nuestra vida: del sexo pasamos a la posibilidad del erotismo por el que buscamos, de forma trágica, aquella continuidad perdida, una suerte de fusión con el otro que supone nuestra propia disolución y que es el inicio de toda comunidad verdadera.

Así tenemos que "no es la necesidad sino su contrario, el 'lujo', lo que plantea a la materia viviente y al hombre sus problemas fundamentales"15. Esta es la tesis que destruye de un lado al liberalismo burgués y de otro al socialismo marxista que comparten un mismo interés por el concepto de trabajo como movilizador de las fuerzas humanas: para el marxismo la naturaleza humana se define como trabajo, como aquella acción sobre la naturaleza que hace posible su objetivación y apropiación y, con ello, la libertad humana. En este esquema, será el proletariado, ahora esclavo, el que pase a ser el amo precisamente por la fuerza de su trabajo. Así, la libertad soñada no puede realizarse si no es en el plano material mediante la debida transformación de las relaciones económicas que acabe con el trabajo asalariado por el cual el hombre queda reducido a mercancía. Se desvela aquí también un cierto optimismo, un sentido de la historia como progreso que viene de la Ilustración y pasa por Hegel, pero también, una filosofía de la sospecha que encuentra que por debajo de las ideologías se haya esa infraestructura material latente que provoca el cambio en la historia. El capitalismo se presenta como el paso necesario hacia la era comunista, pues el imperialismo burgués se hace sepulturero de sí mismo. Éste será el efecto de la última lucha de clases que viviría la historia, una lucha a tres niveles: material (contra el burgués capitalista); político (contra el Estado que defiende los intereses de la clase

${ }^{15}$ G. Bataille, La parte maldita precedida de La noción de gasto, Barcelona, Icaria, 1987, p. 50. 
dominante); e ideológico (contra la superestructura que apoya con ideas al sistema opresor).

Historia como progreso y trabajo en pos de la acumulación: principio de utilidad en ambos casos. En el caso de Marx ya con Max Weber podemos entender la crítica batailleana: Marx eleva a principio metafísico las relaciones económicas para el análisis histórico de modo que todo cobra significatividad desde el materialismo y sólo desde él. La filosofía de la sospecha marxiana se articula desde una antropología que entiende al hombre como homo oeconomicus y desde ahí como ser social. Pero además este homo oeconomicus sostenido desde el marxismo no da cuenta de todos los fenómenos de la vida humana y ha contribuido, al igual que el liberalismo, a ocultarlos: "Que, en definitiva, se deba gastar sin miramientos (sin contrapartida) la energía que constituye la riqueza, que una serie de operaciones lucrativas no tengan decididamente otro efecto que el vano despilfarro de sus beneficios, esto es lo que rehúsan los espíritus habituados a ver en el desarrollo de las fuerzas productivas el ideal de la actividad (...) Pasar de las perspectivas de la economía restringida a las de la economía general comporta, en verdad, un cambio copernicano: la puesta al revés del pensamiento y de la moral"16. Y este cambio viene originado por la puesta al descubierto de esa parte maldita que barre toda hipocresía de modo que el ser humano pueda tomar conciencia de este movimiento inevitable y gestionarlo satisfactoriamente.

El principio de pérdida, la parte maldita, es también la dimensión que Bataille viene a llamar sagrada, en contraposición al orden profano del trabajo. En éste último lo que se busca es la sobrevivencia y, en consecuencia, lo que mueve es el miedo a la muerte y, por tanto, su evitación. De ahí que siempre se deba ganar, siempre se deba obtener beneficio y acumular energía. Por eso Bataille introduce el descubrimiento del útil como un momento importante de la antropogénesis. Nos dice, "la posición del objeto, que no está dada en la animalidad, lo está en el empleo humano de los útiles (...) el útil introduce la exterioridad"17. Por tanto, es por la invención de la herramienta que se rompe aquel continuum animal inmanente en el que permanecíamos antes de ser seres humanos como tales: el útil inaugura la humanidad pero es también, en parte, su ruina. La objetivación del mundo, la separación consciente del individuo humano con respecto al mismo, es recursiva puesto que supone también la objetivación del sí mismo, es decir, implica a su vez la subordinación del sujeto mismo que se convierte para sí en objeto-útil y, por ende, también del Otro. El hombre ahora puede pasar a ser una cosa, un medio para un fin ulterior, y, aun más: "el mundo de las cosas es sentido como una decadencia. Arrastra la alienación de quien lo ha creado (...) La herramienta cambia juntamente a la naturaleza y al hombre que

\footnotetext{
${ }^{16}$ Ibidem, pp. 58-61.

${ }^{17}$ G. Bataille, Teoría de la religión, cit., p. 31.
} 
la fabrica y la utiliza (...) La naturaleza se convierte en propiedad del hombre, pero deja de serle inmanente. Es suya a condición de estarle cerrada (...) Todo lo que está en mi poder anuncia que he reducido lo que me es semejante a no existir por su propio fin, sino por un fin que le es extraño"18. Hasta aquí se cumple la negatividad teorizada por el sistema especulativo hegeliano en cuanto a la objetivación del mundo y, también, el materialismo marxista en tanto que es el trabajo lo que se sitúa en el epicentro de este mundo profano de la necesidad.

Pero la muerte, si bien está detrás de la necesidad y del tiempo del mundo profano como tiempo cronológico en una secuencia medios-fines, también tiene una doble faz: ella es capaz de revelar que el mundo no se reduce a la utilidad porque ella misma no es útil, porque con ella se efectúa la dilapidación de la vida misma. Esta es su negatividad sans emploi y por ella se abre ese otro mundo distinto del mundo profano que es el mundo sagrado. En este punto Bataille nos habla del sacrificio que trata de describir a través de las prácticas de los pueblos primitivos y que nos muestra como cualquier derroche implica un tal sacrificio porque de lo que se trata es de deshacer la dimensión útil de la cosa, de manera que, de hecho, deje de ser una cosa. En eso consiste la fascinación del sacrificio, pero también, de ahí la repulsa que puede causarnos. ¿Cómo admitir sin angustia que hay una dimensión que no podemos controlar porque se escamotea a la utilidad, que no sirve? ¿Qué clase de goce puede producirnos aquello que nos gasta y, en consecuencia, nos acerca a la muerte?

Esta dialéctica sin reconciliación de contrarios entre el principio de pérdida y el principio de utilidad rompe toda posibilidad de entender la historia como progreso y la prefigura como historia trágica de un litigio irresoluble e inevitable, pues toda vez que la acumulación llega a cierto nivel de saturación, el excedente es derrochado de un modo u otro. Y, así, se abre una dimensión no atenta a la escasez y a la necesidad de acumulación sino a la superabundancia y a su dilapidación. Este principio, es condición de posibilidad de toda heterología, esto es, de la ciencia capaz de estudiar todo lo que excede y lo que, por tanto, difiere: "Pensamiento de la exclusión, de la expulsión, de la separación, (...) De la actividad sexual al gasto sin freno, pasando por los tabúes, los sollozos y el éxtasis religioso, Bataille cita los comportamientos tratados como cuerpo extraño" 19 . Una ciencia que no puede ser abarcada por ninguna de las ciencias convencionales, tampoco por la filosofía, no si éstas se entienden como actos serviles, útiles de algún modo, porque "el trabajo está en el origen de la conciencia y del conocimiento, del saber acerca de sí mismo y acerca del mundo. La propia actividad del conocimiento es para Bataille una actividad laboral" ${ }^{20}$.

\footnotetext{
${ }^{18}$ Ibidem, pp. 44-45.

${ }^{19}$ F. Marmande, Bataille político, Buenos Aires , Ediciones Signo, 2009, pp. 60-61.

${ }^{20}$ A. Campillo, Contra la Economía. Ensayos sobre Bataille, cit., p. 25
} 
Pero también es el oscuro principio rector del erotismo y, en consecuencia, esta heterología sería también la encargada de dar cuenta del Otro y los modos de relación con él. La heterología se encargaría entonces de la parte que la Economía restringida ha ignorado. Sucede que si no puede parecerse a una ciencia en sentido tradicional entonces sólo puede adoptar el lenguaje de la poesía al igual que sucedía cuando tratamos de acercarnos al mundo de la animalidad. Y esto porque si el principio de utilidad, con el hallazgo del útil y la separación sujeto-objeto que instaura, nos aleja de ese mundo, el principio de pérdida es el único capaz de acercarnos. Pero, ya lo hemos dicho, aquí no hay ni telos ni necesidad ni finalidad de ningún tipo. Ni es posible la libertad por la auto-conciencia plena al modo hegeliano, ni lo es en una reconquista de la dimensión animal. Lo único que queda es el instante que rompe el tiempo lineal $\mathrm{y}$, por un momento, nos hace soberanos al conjurar el miedo a la muerte ${ }^{21}$.

Hasta aquí de algún modo hemos descrito círculos concéntricos: de aquél quid fenomenológico y quizá más especulativo hemos pasado a la cuestión material, económica en sentido amplio. Ahora nos adentraremos en la dimensión moral. Poco a poco la figura completa dibujará todas las direcciones en torno a la comunidad y a la comunicación. Nos vamos acercando.

\section{En la cumbre moral}

Tal vez los más explícitos y bellos fragmentos los encontremos en Sobre Nietzsche, voluntad de suerte. Allí esa comunidad que luego Roberto Esposito calificaría de impolítica se perfila como el único lugar habitable para el ser humano dados los caracteres existenciales que apuntó en su tiempo Heidegger y luego Sartre. Así, finitud y ateísmo son las dos marcas distintivas de este hombre y sólo por ellas es capaz de comunicarse y, por extensión, de crear comunidad. Sólo un hombre que se sabe herido de finitud, precario, sin guía ni patrón, puede darse en sacrificio al Otro, en cambio un ser acabado, pleno, infinito y perfecto no es capaz de esta forma de donación de sí. La imperfección, el no-saber y la muerte son las condiciones de posibilidad del habla y la escucha, de la conexión entre los hombres, del lenguaje original y origi-

\footnotetext{
${ }^{21}$ No es de extrañar que en muchos momentos Bataille traiga en sus textos a Kierkegaard. Considerado el padre del existencialismo, el estadio religioso que describe el danés y al que sólo puede acercarse desde un lenguaje estético, marca el arrojo al absurdo del individuo que, como Abraham, aquel héroe trágico de Temor y Temblor se ve transido de un horror que, sin embargo, no le detiene en su misión ex-tática. La fe kierkegaardiana se coloca por encima de la muerte y de todas las convenciones del estadio ético del hombre masa. En S. Kierkegaard, Temor y temblor, Madrid, Alianza Editorial, 2001. Igualmente oímos las resonancias heideggerianas y aquél ser-para-lamuerte de la ontología fenomenológica y el análisis existenciario del Dasein en que la angustia le despierta de la vida in-auténtica del se impersonal (Das Man), en M. Heidegger, Ser y Tiempo, Madrid, Trotta, 2003.
} 
nante. Podríamos decir que es una cuestión de necesidad: el ser humano necesita comunicarse por y a través de sus carencias, de su ser errático, de la tragedia que lo configura hasta el fondo. Pero la paradoja aparece si estamos en condiciones de entender que la comunicación supone a su vez una pérdida de sí, la disolución en el otro de un ser ya por sí precario: "los seres, los hombres, no pueden 'comunicarse' -vivir- más que fuera de sí mismos. Y como deben 'comunicarse', deben querer ese mal, la mancha, que poniendo su propio ser en juego, los vuelve penetrables el uno para el otro (...) Es derruyendo en mí mismo, en otro, la integridad del ser, como me abro a la comunicación, como accedo a la cumbre moral"22 Esta cumbre supone pues una forma de gasto improductivo, un derroche de sí, una destrucción sin cálculo que tiene su opuesto inevitable en un ocaso en el que predomina la conservación y la utilidad mediante aquella razón instrumental weberiana ${ }^{23}$.

Ahora todo lo que hemos desarrollado hasta aquí cobra una nueva luz (o, mejor, se oscurece). Aquella negatividad sans emploi de la que Hegel había huido en pos de una sabiduría que al cabo se revelaría servil, el principio de pérdida que da lugar a una Economía general no sólo atenta a los fenómenos de la acumulación y la escasez, la heterología como pensamiento de lo que excede, la historia como litigio irresoluble sin conciliación, la afirmación de aquella parte maldita, etc. Todo está dispuesto como en una constelación en torno a la necesidad de comunicación, de esa vuelta al continuum donde el Otro ya no es un objeto y, por tanto, donde no hay ya sujeto tampoco. Pero esperemos un poco más para detenernos en el significado de la Experiencia interior y llegar al Nietzsche de Bataille.

La experiencia interior que Bataille propone "es la puesta en cuestión (puesta a prueba), en la fiebre y la angustia, de lo que un hombre sabe por el hecho de existir (...) un viaje hasta el límite de lo posible para el hombre. Cada cual puede no hacer ese viaje, pero, si lo hace, esto supone que niega las autoridades y los valores existentes, que limitan lo posible"24. Sin embargo, hay que entender que en absoluto su-

\footnotetext{
${ }^{22}$ G. Bataille, Sobre Nietzsche. Voluntad de suerte, trad. de F. Savater, Madrid, Taurus, 1989, pp. 54-55.

${ }^{23} \mathrm{Al}$ mismo tiempo que Bataille compone su ampliación del principio de escasez por el principio de gasto, la escuela de Frankfurt y, sobre todo, Horkheimer, reelaborando las tesis weberianas sobre la razón instrumental, compondrán su crítica a la sociedad capitalista también de la mano del marxismo. Sobre todo en su Crítica de la razón instrumental, Horkheimer nos pone sobreaviso de los peligros del primado de esa razón subjetiva que lo somete todo al encadenamiento mediosfines, un tipo de razón que únicamente conduce al hombre hacia su propia auto conservación en tanto que le dispone a la consideración calculatoria, estratégica, para la consecución de un objetivo: "La razón subjetiva se revela en última instancia como la capacidad de calcular probabilidades y determinar los medios más adecuados para un fin dado". M. Horkheimer, Crítica de la razón instrumental, Madrid, Trotta, 2010, p. 46.

${ }^{24}$ G. Bataille, La experiencia interior, seguida del Método de meditación y del Post-scriptum 1953, trad. de F. Savater, Madrid, Taurus, 1986, pp. 14-17.
} 
pone un paréntesis, al modo cartesiano o husserliano, para luego llegar a certidumbres. Este método de meditación no llega a reposo alguno, no busca sostener ningún edificio científico y tampoco busca a Dios porque no busca NADA, se mantiene en el no-saber. "La experiencia no conduce a un lugar de salvación, sino que, más bien exige el sacrificio, la perdición, la inmolación del sujeto que la padece" ${ }^{25}$. Lo que se niega aquí en el fondo no es otra cosa que el reino práctico de la utilidad, de la dicotomía sujeto-objeto por la que el hombre se apropia del mundo y de sí mismo, de la acción que siempre queda sujeta a fines. Sólo así se alcanza la soberanía por la cual el hombre se libera de toda cadena, de toda forma de trascendencia. Se trata, pues, de una soberanía en que no tiene sentido el miedo a la muerte, que es plena afirmación de la vida como exuberancia y derroche de sí misma: "la comprensión de la soberanía como renuncia al cálculo y afirmación del azar y del presente, se alzan como las dos influencias decisivas de Nietzsche en Bataille" ${ }^{26}$. Será ésta, como veremos, la misma experiencia que se da en el erotismo donde se vehicula la comunicación y por la que puede darse el paso a la comunidad.

Y con esta afirmación de la vida, ya en Sobre Nietzsche, voluntad de suerte, establece dos pares más que, sin duda, tienen conexión con aquellos principios de pérdida y de utilidad, (igualmente con lo homogéneo y lo heterogéneo, lo sagrado y lo profano): la moral de la cumbre y la moral del ocaso. Y es aquí donde rescata a Nietzsche de las interpretaciones que le colocan del lado del antisemitismo y el nazismo alemán porque la voluntad de poder se torna ahora, con Bataille, voluntad de suerte (chance).

El filosofar a martillazos del alemán supone el último asesto de muerte a la conciencia ilustrada. El martillo es la herramienta destructora que evidenciará el sonido a hueco de las verdades tradicionales, de los grandes sistemas, de la metafísica, la moral y el cristianismo. Su filosofía de la sospecha quiere desculpabilizar definitivamente la voluntad, quiere dar al traste con los viejos supuestos metafísicos que mantienen al hombre sin posibilidad de crecimiento. Se muestra como un profeta, el profeta que anuncia al superhombre y su libertad lograda en la consabida transvaloración de los valores. Por eso la moral de la cumbre batailleana consiste en dar de sí a aquella parte maldita: "La cumbre responde al exceso, a la exuberancia de las fuerzas. Lleva a su máximo la intensidad trágica. Se conecta con los gastos de energía sin tasa, con la violación de la integridad de los seres. Luego está más próxima del mal que del bien" 27 .El punto de partida nietzscheano será oponer al ascetismo schopenhaueriano la afirmación y la exaltación de la vida cuyo ejemplo histórico lo encuentra en los antiguos helenos antes de la emergencia de la figura de Sócrates, del

\footnotetext{
${ }^{25}$ A. Campillo, Contra la Economía.Ensayos sobre Bataille, cit., p. 87.

${ }^{26}$ A. Galindo, op. cit., p. 126.

${ }^{27}$ G. Bataille, Sobre Nietzsche. Voluntad de suerte, cit., p. 48.
} 
racionalismo y el concepto, esto es, lo encuentra en el espíritu dionisiaco. Dionisos, como divinización de la aceptación infinita del la vida, como negación de todo orden, de todo lo racional, esto es como refutación a la famosa tesis hegeliana que afirma que "todo lo racional es real y todo lo real es racional". Así, el superhombre constituye la superación del hombre por el hombre, la voluntad de vivir, es el salto desde el nihilismo más oscuro, el nihilismo que en último término es voluntad de nada, voluntad de negar la vida. ¿Qué niega exactamente desde el principio la vida decadente, el nihilismo y el egipticismo?, ¿a qué se refiere Nietzsche cuando habla de la vida? Es el devenir, lo múltiple, a lo que deja encerrado en categorías inferiores tales como "la apariencia', aquello que, nos dijeron, lleva a engaño. Y, por encima de ellos, como única meta verdadera a alcanzar queda el Ser, lo Uno. De este modo la ontología metafísica ha falseado la realidad queriendo hacer pasar por verdad lo que sólo es una ilusión, una ficción, mientras que rechaza como falso lo único real. De ahí proviene "el ocaso - que responde a los momentos de agotamiento, de fatiga- concede todo el valor al cuidado de conservar y enriquecer el ser. De él provienen las reglas morales" ${ }^{28}$. Aquí se cifra, pues, la moral del ocaso.

Pero esto, en el fondo, es sólo la consecuencia de un poder horrible, ilegítimo, que se abre paso y se afirma a sí mismo desarrollando la fuerza decadentista que forja las sociedades desde Sócrates y Platón hasta llegar como culmen al cristianismo, al pietismo kantiano y al hegelianismo. Se trata de fuerzas reactivas, de las fuerzas de la masa inferior que se alzan portadoras del resentimiento y se agrupan como rebaño. Ahora bien, en este punto Bataille se aleja de Nietzsche y su aristocratismo y es el momento en que trata de conciliarlo con Marx. La moral del la cumbre no se encierra en parámetros elitistas sino que es una dicotomía "inherente a la existencia humana como tal, y por tanto no cabe establecer jerarquía alguna entre dos tipos diferentes de hombre" 29 . Recordemos además que igualmente ha dinamitado la forma de soberanía hegeliana de manera que desplaza la diferencia entre soberanía y servidumbre al par derroche/utilidad.

Por último aun hemos de hablar del profeta Zaratustra, el anunciador del cambio, el descriptor de las tres transformaciones del alma, el que conoce al camello que carga con los ideales morales, el que ha visto al león luchar y romperlos, el que anuncia al niño creador desde la nada. Y ahí, en el niño capaz de jugar, está la clave, pues "jugar es, en primer lugar, no tomar en serio. Y morir...” ${ }^{30}$, es darse por entero y llegar a perder sin que esto importe. Zaratustra es el profeta de Dionisos, el que anuncia la caída definitiva de los ídolos, de las viejas ideas y moralinas, el derrumbe de los anteriores

\footnotetext{
${ }^{28}$ G. Bataille, Sobre Nietzsche. Voluntad de suerte, cit., p. 48.

${ }^{29}$ A. Campillo, Contra la Economía Ensayos sobre Bataille, cit., p. 101.

${ }^{30}$ G. Bataille, Sobre Nietzsche. Voluntad de suerte, cit., p. 120.
} 
sistemas filosóficos, la superación del cristianismo y del cristianismo mundanizado tras la muerte de Dios a manos del hombre más feo, ese que ha cargado las espaldas de la humanidad todo el peso del ideal divino que, al cabo, no existe sino que es el mayor de los errores edificado desde el miedo y la decadencia. Pero hay una parte de Nietzsche que no se ha entendido debidamente o que, tal vez el propio Nietzsche debió aclarar, nos dice Bataille: es aquella voluntad de poder por la cual el niño juega despreocupado donde se encuentra "la confusión entre soberanía y potencia"31. Esta confusión nos devuelve otra vez al campo de batalla con el que se enfrenta el francés: la potencia, la proyectualidad tiene que ver con el reino de los medios y los fines, en cambio la soberanía no se rinde a objetivo alguno y, por eso, configura al niño y a su recreo y es así que la voluntad de poder es para Bataille voluntad de suerte (chance). Lejos de la razón instrumental y calculatoria, aquí nos arrojamos al más puro azar, a lo imprevisible. Y aquí es donde Marx no tenía razón al tratar de proyectar su revolución porque "la revolución, si lo es efectivamente, no puede ser objeto de un proyecto programado de antemano" 32 .

Con todos estos elementos podemos adelantar varias conclusiones: en primer lugar la comunidad batailleana no establece jerarquías y, por eso, es siempre abierta. Pero no sólo por eso, también por la naturaleza del tiempo en que se da, el instante imprevisible, el azar en el que jugamos y nos jugamos. Y, este juego de continuo abierto al otro es lo que nos dispone a buscar (sin buscar) la continuidad perdida que de algún modo oscuro tira de nosotros. Es en la moral de la cumbre donde nos perdemos en la indistinción, donde verdaderamente podemos estar juntos y comunicarnos sin aquella separación en que nos sitúa la moral del ocaso.

Hagamos un paréntesis ahora: En 1939 Georges Bataille escribe El Culpable, un diario en que no pretende hablar de la contienda mundial que se ha desencadenado, de la violenta decadencia en que ha caído Europa con la emergencia totalitaria, sino que ofrece unas palabras que se presentan como donación de sí para un lector indeterminado, para un Otro indefinido, como un refugio paradójico en el que seguir perdiéndose aun más en la que fue, lo hemos visto, una de las épocas más difíciles de su vida. Confiesa: "ya apenas leo, un exceso de trabajo me fatiga (...) vivo en el interior de una tumba". No sólo las circunstancias históricas tienen que ver en la confección de este escrito, también la tragedia personal le devora: la muerte de Colette Peignot, Laura, su amante, impregna todo el escrito. En El aleluya que acompaña a la edición que manejo encontramos el relato del tiempo en que Bataille vivió su agonía final. A mi modo de ver es aquí donde Bataille no sólo teoriza sobre su idea de comunicación y comunidad, sino que más bien la ejerce mostrando su herida, aquella abertura san-

\footnotetext{
${ }^{31}$ R. Esposito, "La comunidad de la muerte", en Categorías de lo impolítico, Buenos Aires, Katz, 2006, p. 296.

${ }^{32}$ A. Campillo, Contra la Economía. Ensayos sobre Bataille, cit., p. 102.
} 
grante en la piel del yo por la que puede fluir hacia un otro, la vivencia de la finitud y el no-saber que llevan al éxtasis erótico en su vinculación con la muerte como experiencia en el extremo de lo posible...

\section{El juego de Eros. Comunidad y Comunicación}

Se trata del erotismo de los amantes que añade la dimensión afectiva a la sexualidad humana e incluye la angustia y el sufrimiento de saber que romper por completo y para siempre la discontinuidad es imposible. En el instante supremo del gozo, en la convulsión de la pasión, al amante le parece que sólo a través de su amado pueden romperse los límites de su subjetividad y posibilitar de este modo la fusión con él. De ahí que la muerte entre en este juego amatorio: amar significa, de algún modo, querer morir y querer matar. Por otro lado, ese sufrimiento por la imposibilidad de instaurar el continuum con el amado más que en breves instantes fugaces, es la prueba de la diferencia del Otro y justamente lo que nos mueve a buscarlo (sin buscarlo). La comunicación es entonces guiada por una nostalgia bifaz: la nostalgia de la disolución del yo y de la disolución del otro, es decir, nostalgia de la fusión, de la indiferenciación de los yoes precisamente por su diferencia insalvable en cuanto que humanos.

No obstante Bataille nos dice que "tanto en el erotismo de los corazones como en el erotismo sagrado (...) la perturbación erótica inmediata nos da un sentimiento que lo supera todo; es un sentimiento tal que las sombrías perspectivas vinculadas a la situación del ser discontinuo caen en el olvido" 33 . Por tanto, ambos se encontrarían en el mismo nivel. Éxtasis, orgasmo y muerte se tocan. En este contexto podemos comprender los pasajes en que Bataille nos habla de la divinidad herida, de la figura de Jesucristo, ese dios hecho carne y dispuesto para la muerte, condición de posibilidad ésta de comunicación con los hombres y modo por el cual el cristianismo consiguió universalizarse.

Eros y Thánatos. Sexualidad desentendida de afán reproductivo y angustia ante la muerte. Dos pulsiones netamente humanas que atormentan y dan forma al hombre desde que este es. Y es que, quizás, por ellas "es". Dos aspectos tan aparentemente antitéticos son enlazados por Georges Bataille como en un enclave ineludible alrededor del erotismo, definiendo a este -en su obra homónima- como "la aprobación de la vida hasta en la muerte" 34 .

Por la hondura y capacidad desestabilizadora de estas dos emociones, desde su constatación en la prehistoria se hizo necesario algo que las amarrase para poder vivir en sociedad, naciendo así las prohibiciones y los tabúes y es por ello que no existen mayores que aquellos destinados a confinar a ámbitos muy concretos la muerte y lo

\footnotetext{
${ }^{33}$ G. Bataille, El erotismo, Barcelona, Tusquets, 1979, p. 17.

${ }^{34}$ Ibidem, p. 8.
} 
sexual. Al cuerpo muerto y al cuerpo desnudo. Miles de años atrás se erigieron las más poderosas normas morales convirtiéndolas en diques contra la lujuria y la aniquilación y estas debían ser entroncadas con algo que les permitiera mantenerse incólumes, no existiendo nada más sólido para este fin que "lo sagrado". Pero con la norma, nacen las transgresiones, la atracción por lo prohibido, la repulsa ante el pecador y la fascinación por el pecado, las serpientes, las manzanas y aquellos paraísos de los que resulta inevitable ser expulsado para existir. Este ha sido es y será el caballo de batalla de las religiones, quedando lo erótico y el estremecimiento ante la muerte confinado a este lado del existir, a la materia, a algo que Bataille anacrónicamente define como "lo diabólico". Esta tensión desgarradora se extrapola a un orbe más general, al de los medios y los fines. Garantizar la vida, de un modo civilizado por medio del trabajo, pero el ser humano no se agota ahí. Y por ello a veces no entiende de razón, porque el fin es esclavo del deseo y en él se consume. El éxtasis -místico, poético, sexual...- es el instante que nos culmina, el fulgor. Cual Sísifo, el ser humano soporta una vida llena de medios para latir ardiendo en la eternidad del fin y al querer aprehender este, comprobamos que siempre se ha desvanecido y que nos hallamos, de nuevo, en el fatigoso tramo del sudor y de las renuncias. El deseo es combustión y la razón apilar leña.

En síntesis tenemos el éxtasis unido al erotismo (bien sea sagrado o de los corazones), éste como disolución del yo e intento de retorno a la continuidad perdida a través del otro amado, en definitiva, Eros y Thánatos jugando peligrosa e inexorablemente. Este erotismo requiere pues que las partes prestas a fusión no estén cerradas sino, al contrario, heridas de finitud, de muerte. Así se produce la comunicación soberana que es supresión de la conciencia individual y riesgo de destrucción para aquellos dispuestos a ponerse en juego. El erotismo se ve entonces claramente desde la perspectiva del despilfarro, del gasto inútil del que el otro es partícipe en la misma medida, donde no se trata de adueñarse del amado sino de perderse también.

Pero no sólo a los amantes y a lo divino se asocia este erotismo. También a las artes plásticas y, como no, a la literatura y a la poesía, esas que a las que el propio Bataille se dedica. Las letras, pues, también guardan una especial ligazón con el mal y responden a esa posibilidad comunicativa ${ }^{35}$. Su gusto por Baudelaire, Sade o Kafka nos habla de esta identificación. En consecuencia, por ellas también podemos hacer comunidad tal y como le sucedió al propio Bataille con Nietzsche, una forma de comunicación que va más allá de la comunicación funcional del lenguaje ordinario y que se plasma en su propia estilo de escritura confesional, en sus novelas y en sus poemas.

\footnotetext{
${ }^{35}$ El lugar donde más claramente podemos encontrar esta asociación dispuesta por Bataille será en La literatura y el mal, trad. L. Ortiz, pref. R. Conte, Madrid, Taurus, 1987.
} 
Aun más, podemos localizar un símbolo plástico de la comunidad batailleana en la representación del hombre sin cabeza portada de la revista Acéphale que el propio Bataille fundó y que él mismo nos describe así: "El hombre se escapó de su cabeza como el condenado de la prisión. Encontró más allá de sí mismo no a Dios, que es la prohibición del crimen, sino a un ser que ignora la prohibición. Más allá de lo que soy, encuentro a un ser que me hacer reír porque no tiene cabeza, me llena de angustia porque está hecho de inocencia y de crimen: sostiene un arma de hierro en su mano izquierda, unas llamas similares a un sagrado corazón en su mano derecha. En una misma erupción reúne el Nacimiento y la Muerte. No es un hombre. Tampoco es un dios. No es yo, pero es más que yo: su vientre es el dédalo en el que se ha extraviado, en el que me extravío con él y me recobro siendo él, es decir, monstruo". ${ }^{36}$

¿Qué se esconde detrás de esta metáfora visual (el dibujo de André Masson)? Por Blumenberg sabemos que la potencia de la metáfora a la hora de generar y construir el imaginario político, del que forma parte la cosmovisión de un determinado individuo, no debe ser desdeñada en pos del mero concepto pues ésta puede completarlo e incluso llegar allí donde aquél no alcanza. Bataille, lo hemos visto, está plagado de ellas, pero en esta encontramos la visualización exacta de su modo de entender la comunidad. Esta metáfora trata de reseñar un intento por insertar un mito nuevo, un mito ateo que asuma hasta el final la tesis de Nietzsche sobre la muerte de Dios, el mito del hombre sin el principio rector de la razón, secularización moderna del dios medieval y herencia, a su vez, de la filosofía platónica y de aquél Supremo Bien instalado en el mundo celeste de las Ideas. En suma, "sin padre, sin patria y sin patrón". Una vez más, metáfora contra metáfora, porque, recordemos, para Nietzsche todo el pensamiento era sólo eso, la sucesión de metáforas una tras otra. A la de Dios y todas sus secularizaciones modernas se opone aquí la del monstruo acéfalo.

Algo similar sucedía en el Dossier de l'Oeil Pineal y Anus Solaire, donde de lo que se trata es de construir un nuevo mito, una explicación antropológica para el surgimiento del hombre que lo emparenta con el gusano y añade, al supremo órgano de la vista que en Platón era receptor de la luminosidad del Sol y de la verdad, un ojo pineal que, por el eje horizontal contrapuesto al vertical "es la inversión de nuestra analidad: es un volcán asentado en el centro de nuestro cráneo: ano solar" ${ }^{37}$. Transgresión ésta y ataque al corazón de la conciencia moderna y la filosofía tradicional que va de Platón a Hegel: donde Descartes vio el habitáculo del alma, allí donde se encontrarían las ideas innatas y, entre ellas, la idea de Dios, Bataille encuentra excrecencia anudando lo alto a lo bajo y haciendo al primero dependiente del segundo.

\footnotetext{
${ }^{36}$ G. Bataille, "La conjuración sagrada" en La conjuración sagrada, Ensayos 1929-1939, Buenos Aires, Adriana Hidalgo editora S.A., 2003, p. 226.

${ }^{37}$ M. Morey, “Excessere omnes.... Invitación a la lectura de Georges Bataille”, op. cit., p. 188.
} 
El monstruo acéfalo frente al que nos encontramos ahora en este análisis supone otro gesto transgresor: su ser sin cabeza alude a la falta de fundamento teleológico, de orientación, de razón y, así, de utilidad. Es el monstruo del derroche, de lo que es expelido al infinito y no tiene patrón ni guía, de lo inmotivado. Otra vez, metáfora contra metáfora, bien podríamos contraponerlo a la imagen de la portada del Leviatán hobbesiano, ese otro monstruo que lo que promete es la seguridad a un mundo amenazado por las pasiones y que se coloca en trascendencia a la ley misma que lo funda, a los contratantes que alienan su poder para entregárselo por completo. Aquí está la clave y aquí podemos comenzar a tirar de la madeja del antiestatalismo batailleano y, sobre todo, de la dicotomía que puede establecerse entre el modo de comunidad impolítico de Bataille y la teología política cuyo máximo representante es sin lugar a dudas Carl Schmitt: "El blanco (...) es la reductio ad unum de la teología política fascista" 38 .

Sabemos que Bataille se colocó como firme opositor y denunciante de la creciente acumulación de poder por parte de los Estados y, así, contra el surgimiento del totalitarismo nazi y fascista. En El problema del Estado proponía una revolución que movilizara aquellas fuerzas proletarias, tales como la angustia y la desesperación, capaces de aminorar el alto nivel coercitivo de los estados. Al mismo tiempo, su llamada al proletariado le hacía hostil también a la sociedad liberal-burguesa. Por otro lado, en La estructura psicológica del fascismo exponía que sólo arrebatándole al fascismo los elementos heterogéneos que había sabido gestionar para hacer implosionar la democracia habría alguna posibilidad de vencerlo. Este es el punto en que Marx y Nietzsche se unen, en que igualdad y libertad han de ser ir de la mano. Pero los tiempos de Acéphale y del Colegio de Sociología Sagrada suponen una vuelta de tuerca y completan este modo de entender el problema político que se profundiza mucho más. Aquí se gesta la verdadera dimensión impolítica de Bataille tal y como la recoge Roberto Esposito en La comunidad de la muerte, capítulo de su obra Categorías de lo impolítico dedicado a Bataille.

La recuperación de los elementos heterogéneos, sagrados, continúa ahí, de lo que Bataille acaba por deshacerse es de la propensión a entender la comunidad como una obra que se sustente, al contrario, "en el exorcismo de la muerte (...), la communauté de coeur batailliana es en cambio y ante todo comunidad de muerte" ${ }^{39}$. Ahora ha de venir a nuestra mente todo lo dicho acerca del diálogo entre Hegel y Bataille en Hegel, la muerte y el sacrificio y, del mismo modo, todo lo dicho acerca del erotismo y del azar, de la comunicación y la disolución de los seres, de la pérdida improductiva y la donación de sí. La comunidad se sostiene inmanente, sin fundamento externo a sí misma, en la posibilidad de fusión y disolución de los individuos heridos de muerte,

\footnotetext{
${ }^{38}$ R. Esposito, op. cit., p. 307.

${ }^{39}$ Ibidem, p. 314.
} 
una posibilidad que da justamente el hecho de su aislamiento, de la discontinuidad que inaugura la humanidad en su emergencia al dejar atrás la animalidad. Es la existencia de la otredad, diferente del sí mismo, lo que es condición de posibilidad del comunitarismo que sustenta el francés, porque ella atrae para la aniquilación de la subjetividad separada. Muy al contrario, la ontología política schmittiana y su decisionismo estatalista se coloca en el horizonte de la homogeneización al establecer el par amigo/enemigo y situar en la posibilidad de dar muerte, del asesinato político, el fundamento para una comunidad cerrada que, por serlo, habrá de enfrentarse siempre a un otro diferente que se le opone. Además este fundamento se coloca fuera, extramuros de la dinámica de la comunidad que funda y, en consecuencia, se hace trascendente: "La Teología política de la soberanía es definida a partir de un concepto límite: la decisión sobre el estado de excepción (...) Y esto significa monopolio de la decisión 'en' la excepción, ya que si la soberanía es creación (ilegal) de la ley, ésta es legitimación de tal ilegalidad: ley de la excepción (...) El tránsito de lo trascendente a lo inmanente precisa de la emergencia de la figura personal (un nuevo Dios) que decida la excepción y represente la idea de derecho" ${ }^{40}$.

${ }^{40}$ A. Galindo, op. cit., pp. 54-55. 